\title{
Movimento ao interior da personagem: fissuras na tensão mínima em Caetés, de Graciliano Ramos
}

\author{
Pedro Barbosa Rudge Furtado e Maria Célia Leonel
}

\begin{abstract}
RESUMO: O objetivo do presente artigo é assinalar o surgimento, mesmo que embrionário, da introspecção em Caetés, característica marcante em obras posteriores de Graciliano Ramos. Trata-se de ampliar o modo como a crítica tem avaliado essa narrativa e a produção do autor, considerando a primeira, muitas vezes, apenas como romance de costumes, analisando o início da presença do mergulho introspectivo somente em livros que vieram depois. Fazendo uso de alguns textos da fortuna crítica do livro e de estudos sobre o nosso romance, mostramos como Caetés se movimenta entre a tensão mínima e a interiorizada, alterando a sua forma/conteúdo dependendo do momento narrativo.
\end{abstract}

PALAVRAS-CHAVE: Graciliano Ramos; Caetés; romance de costumes; introspecção.

\begin{abstract}
The objective of this paper is to point out the appearing, even if in not largely developed terms, of the introspection in Caetés, which is a remarkable feature in posterior works by Graciliano Ramos. It is proposed a broadening of the way the critics have been studying this novel and other productions of the author, considering frequently the first one only as a novel of manners and analyzing the beginning of the introspective immersion solely in later works. Using some critical texts concerning this novel and papers about the Brazilian novel, it is manifested how Caetés moves between a minimum and an inner tension, modifying its form/content depending on the narrative moment.
\end{abstract}

KEYWORDS: Graciliano Ramos; Caetés; novel of manners; introspection. 


\section{INTRODUÇÃO}

É ponto comum, na fortuna crítica de Graciliano Ramos, a afirmação de que o aspecto fulcral de suas investigações é a sondagem do sujeito. No entanto, o sujeito nunca é representado como indivíduo isolado, mas associado a uma experiência coletiva, social e, portanto, histórica. Segundo Luís Bueno, a propósito das personagens do escritor, a psique não se inventa sozinha, em elucubrações desligadas do fluxo histórico; ao contrário, ela é atravessada

de lado a lado por sua experiência social e até mesmo pelas experiências familiares acumuladas antes do nascimento. $\mathrm{O}$ recalque social pode muito bem estar na base de sentimentos e preferências que à primeira vista se mostram como manifestações da individualidade. ${ }^{1}$

Há, em todas as obras de Graciliano Ramos - desde os romances, passando pelos contos e alcançando os livros de memórias -, uma interação dialética entre personagens em conflito, mais ou menos agravados, com as tensões sócio-históricas. O mundo circundante é, muitas vezes, gerador da desordem, sendo a conciliação com ele aparentemente impossível no âmago dos seres de papel. O diferente - os valores sociais, os outros promovem os embates entre o eu e o mundo. A manifestação de afeto do indivíduo, de acordo com Alfredo Bosi, "não se pode sequer construir sem a experiência da alteridade". ${ }^{2}$ A narrativa literária, consequentemente, figura as incongruências do sujeito no diálogo - superficial ou profundo - com o mundo.

O texto de Caetés (1933) movimenta-se entre a narração dos costumes da elite - por meio da mirada de João Valério em direção à família de Adrião, as práticas do indivíduo médio, a que o protagonista está incorporado - e os seus instantes de mal-estar construídos mediante a representação de sua interioridade. $\mathrm{O}$ foco do narrador-protagonista movimenta-se no meio das pequenas intrigas da cidade provinciana e da subjetivação dos conflitos, que tomam grandes proporções.

1. BUENo, Luís. "Posfácio: uma grande estreia". In: Ramos, Graciliano. Caetés. 32 ed. Rio de Janeiro: Record, 2012, p. 264.

2. воsI, Alfredo. Céu, inferno: ensaios de crítica literária e ideológica. 2 ed. São Paulo: Duas Cidades; Editora 34, 2003, p. 458. 
Tendo em vista o esquema de Alfredo Bosi ${ }^{3}$ em História concisa da literatura brasileira, Caetés relaciona-se, a nosso ver, tanto com o romance de tensão mínima quanto com o de tensão interiorizada. ${ }^{4}$ Sem exaustão, o estudioso define da seguinte maneira, salientando que tais categorias não são estanques, os dois tipos de romance:

Romances de tensão mínima. Há conflito, mas este configura-se em termos de oposição verbal, sentimental quando muito: as personagens não se destacam visceralmente da estrutura e da paisagem que as condicionam. [...]

Romances de tensão interiorizada. O herói não se dispõe a enfrentar a antinomia eu/ mundo pela ação: evade-se, subjetivando o conflito. ${ }^{5}$

É visível a aderência de Caetés aos romances de tensão mínima, uma vez que há a inclinação a minimizar a representação de conflitos sócio-históricos e/ou existenciais, sendo arquitetada, nos momentos de relato de costumes, uma narrativa ligada à paisagem e aos hábitos dos viventes, não havendo grande oposição dramática e desconfortável entre o ser e o querer ser. Em contrapartida, o romance de estreia de Graciliano Ramos traz à tona atributos do romance de tensão interiorizada, principalmente quando João Valério se enovela em si mesmo em monólogos, dando margem para a figuração de embates sócio-históricos e existenciais.

Mostramos, neste artigo, que Caetés - narrativa com tom de crônica de costumes - pode ser visto, na obra de Graciliano, como o livro inaugural no que tange à inadaptabilidade do sujeito diante de sua realidade, por meio da subjetivação dos conflitos, que será aprofundada com afinco em São Bernardo e, principalmente, em Angústia. Inicialmente, cabe lembrar que o relato é feito em primeira pessoa, o que não é comum no romance de costumes. Além disso, é possível assinalar, na obra de estreia, a característica de embrião da "tensão interiorizada" por meio de momentos de ruptura com a crônica de costumes encontrados no texto.

3. Alfredo Bosi adapta, para o contexto brasileiro, o esquema proposto por Lucien Goldmann em Sociologia do romance, que se baseia tanto em ideias de Georg Lukács, de A teoria do romance, quanto em proposições de René Girard, em Mentira romântica e verdade romanesca (Cf. Bosı, Alfredo. História concisa da literatura brasileira. 43 ed. São Paulo: Cultrix, 2006, pp. 418-9).

4. Além dessas duas tendências, Alfredo Bosi assinala, igualmente, a existência dos romances de tensão crítica e de tensão transcendental.

5. BosI, Alfredo. História concisa da literatura brasileira, cit., pp. 418-19, grifos do autor. 
Para atingir o objetivo de demonstrar que a construção de Caetés é alicerçada tanto no romance de costumes quanto no universo de exploração do psicológico, selecionamos e examinamos trechos da obra em que é possível apontar as mudanças da forma narrativa em consonância com o seu conteúdo. Assim, dividimos o nosso texto em duas partes: uma, em que sobressaem os tons de crônica de costumes, já assinalando rupturas, e outro, em que o mal-estar, subjetivado, torna-se mais evidente.

\section{CAETÉS: RUPTURAS NA TENSÃO MÍNIMA DA CRÔNICA DE COSTUMES}

A crônica de costumes apresenta como características centrais, conforme o próprio termo sugere, a fixação de costumes de determinada camada, examinando a dinâmica dos comportamentos sociais. O romance brasileiro mais estudado nesses termos é Memórias de um sargento de milícias, de Manuel Antônio de Almeida. Mário de Andrade, em texto com título homônimo ao do romance, salienta que tal obra se destaca por representar habilmente o estado "de coisas e costumes das vésperas da Independência", ${ }^{6}$ mirando as práticas das camadas sociais mais baixas, o que, então, era bastante raro.

Em termos estruturais, na construção da narrativa que se desenvolve como crônica de costumes, o que sobressai, em Caetés, é o uso reiterado do discurso direto, num relato da história pouco afeito a anacronias entre capítulos. A história é contada mais ou menos cronologicamente, não havendo grande desordem temporal. Dessa forma, o painel social de Palmeira dos Índios - representação fictícia da cidade de mesmo nome - é elaborado no decurso desses diálogos miúdos, de fofocas que remetem a um meio provinciano, onde todos, pelo menos superficialmente, se conhecem. Vejamos um exemplo:

- Uma novidade! — gritou Pascoal quando desdobrei o guardanapo. - A Clementina vai casar.

Era a eterna pilhéria: não se cansavam de forjar casamentos para a pobre da Clementina. — Quem é o noivo? - inquiriu o dr. Liberato erguendo os grossos vidros das suas lunetas de míope.

6. ANDRADE, Mário de. "Memórias de um sargento de milícias". In: Aspectos da literatura brasileira. Belo Horizonte: Itatiaia, 2002, p. 153. 
— Não se sabe - respondeu Pascoal. — Foi um espírito que deu a notícia na última sessão. Clementina ficou atuada...?

Depois de tal conversa, que tem a extensão de sete páginas, João Valério retorna a sua casa, onde o encontram "apático e murcho". O romance é construído pela lógica clássica do tempo, com poucas incursões ao passado distante e ao futuro. Essas escassas incursões, no entanto, são caras ao seu entendimento.

Por meio desse e de outros recursos, temos, na narrativa, a figuração maior do quadro social de uma pequena cidade do que a exploração intensa da interioridade de João Valério - narrador-protagonista. Os conflitos sociais são minimizados em decorrência da narração de acontecimentos banais da província. Entretanto, não é o caso de nos determos na repetição das características, encontradas no romance, de crônica de costumes já destacadas pela crítica. Nosso objetivo é constatar as rupturas em relação a ela.

Sintetizando as características de Caetés, Hélio Pólvora ${ }^{9}$ diz que esse romance é, de fato, "um repositório de cenas da vida na província, com tipos curiosos, ironias, sarcasmos, diálogos ágeis, anotações humorísticas, e, como tempero, o adultério. Uma receita queirosiana". Segundo Antonio Candido, no que toca à atmosfera geral do livro, ela se liga "também à lição pós-naturalista, voltada para o registro dos aspectos mais banais e intencionalmente anti-heroicos do cotidiano e com certo pudor de engatilhar os dramas convulsos de que tanto gostavam os fogosos naturalistas da primeira geração". ${ }^{\circ}$

Todavia, há um adentramento no universo psicológico do protagonista, ainda que não muito acentuado. As personagens secundárias, por sua vez, são um tanto estáticas, o que provém da "relativa frouxidão psicológica" ${ }^{11}$ com que nos deparamos em quase todo o livro. Não há uso intenso do recurso do monólogo interior, o que não nos dá a oportunidade de conhecer João Valério intimamente. Não existe, de fato, em grande parte do romance, introspecção, fazendo com que a vida interior do protagonista se configure graças à sua situação, "num contexto de fatos e acontecimentos".

\footnotetext{
7. Ramos, Graciliano. Caetés, cit., p. 17.

8. Idem, p. 23.

9. Pólvora, Hélio. O espaço interior. Ilhéus: Editora da Universidade Livre do Mar e da Mata, 1999, p. 90.

10. CANDIDO, Antonio. Ficção e confissão: ensaios sobre Graciliano Ramos. Rio de Janeiro: Editora 34, 1992, p. 14.

11. Idem, p. 15 .

12. Idem, p. 19 .
} 
Continuando com Antonio Candido, o parcial desnudamento da personagem em situação - que veremos a seguir - leva o movimento entre o eu e o meio a uma perspectiva dupla, "em que o personagem é revelado pelos fatos e estes se ordenam mediante a iluminação projetada pelos problemas do personagem". ${ }^{13}$ Tal ideia baliza a nossa visão do protagonista, uma vez que, efetivamente, o relato de alguns acontecimentos é acompanhado da introjeção do protagonista. Por exemplo, João Valério frequenta a casa de Adrião, dono da firma comercial em que ele trabalha, e sente, ali - numa esfera mais alta da sociedade a que não pertence -, certo bem-estar:

Uma estranha doçura me invadia, dissipava os aborrecimentos que fervilhavam nesta vida pacata, vagarosamente arrastada entre o escritório e a folha hebdomadária de padre Atanásio. Os velhos móveis, as paredes altas e escuras, quadros que não se distinguiam na claridade vaga das lâmpadas de abat-jour espesso, que uma rendilha pardacenta reveste, tudo me dava sossego. ${ }^{14}$

Esse devaneio rememorativo de João Valério tem como motivação os "dois beijos no cachaço" ${ }^{15}$ que ele deu em Luísa, esposa de Adrião. Depois de tal fato, com ela vexada, o protagonista diz que nunca mais voltará àquela casa. Com a sentença “volto aqui. Adeus", ${ }^{16}$ são desencadeados pensamentos de João Valério referentes àquele círculo social - instalado na casa de Adrião - do qual participava como convidado por ser empregado do dono da casa. A promessa de lá não voltar, entretanto, não é cumprida. Em outros breves momentos de sondagem do interior, avistamos o mal-estar do protagonista em relação a sua situação econômica.

Comparemos parte do trecho citado, em que ele descreve a moradia de Adrião, e um excerto subsequente, no mesmo capítulo, em que ele caracteriza a própria residência, depois de retirar-se apressadamente da casa do patrão, após os dois beijos em Luísa:

Percorri à toa as ruas desertas, envoltas num luar baço, tentando achar tranquilidade no pó e no calor de janeiro. Mais tarde, na hospedaria de d. Maria José, curti uma insônia

\footnotetext{
13. Ibidem.

14. RAMOs, Graciliano. Op. cit., p. 11.

15. Idem, p. 9.

16. Idem, p. 10.
} 
atroz, rolei horas no colchão duro, ouvindo os roncos dos companheiros de casa e conjecturando o que me iriam dizer no dia seguinte os irmãos Teixeira. ${ }^{17}$

A ampla casa de Adrião, de que João Valério apreende a solidez, dá lugar ao colchão duro e ao som implacável do ronco dos demais moradores do local em que vive. Esse mal-estar diante de sua situação econômica percorre toda a obra, principalmente as conversas com os amigos, em que ele diz que Palmeira dos Índios não é o seu lugar, devendo desprender-se e alçar voos maiores; recebendo, por exemplo, uma oferta de emprego, num local que lhe seria mais vantajoso financeiramente, ele responde: "Muito obrigado. Estamos de acordo, mas não aceito a recomendação. Vou para o Rio". ${ }^{18}$

A característica de crônica de costumes que atravessa a narrativa pode manter a leitura do romance nesses traços desconectados da visão crítica sobre a história social. Mas é nos instantes de diferença - isto é, nos momentos de interioridade do narrador-protagonista, embora um tanto isolados - e na sua tentativa de elaboração de um romance histórico sobre os índios caetés, que a prosa permite entrever o choque de valores de João Valério.

A inadaptabilidade espaço-temporal do protagonista que, em Angústia (1936), é nevrálgica, com a narrativa construída num vaivém temporal intenso, ${ }^{19}$ é muito pouco defrontada em Caetés. Há apenas um momento - salvo engano - em que João Valério rememora o seu passado rural: "Iniciei a coisa [a elaboração do romance] depois que fiquei órfão, quando Felícia me levou o dinheiro da herança, precisei vender a casa, vender o gado, e Adrião me empregou no escritório como guarda-livros". ${ }^{20}$ Em outro fragmento, o narrador se mostra indisposto com relação ao seu trabalho, vendo-se inferiorizado por exercer função tão banal:

E eu, em mangas de camisa, a estragar-me no escritório dos Teixeira, eu, moço, que sabia metrificação, vantajosa prenda, colaborava na Semana de padre Atanásio e tinha

\footnotetext{
17. Idem, p. 12.

18. Idem, p. 206.

19. A estrutura temporalmente oscilante de Angústia está ligada ao intenso sentimento de inadequação do narrador-protagonista aos valores do meio em que se encontra quando adulto. Tal sentimento é revelado por meio de diversas retomadas ao passado rural de Luís da Silva. Analisando cada um dos trechos rememorativos, encontramos a fratura e a conseguinte inadaptabilidade do narrador-protagonista a uma nova realidade espacial, econômica, política e social.

20. RAmos, Graciliano. Op. cit., p. 23.
} 
um romance começado na gaveta. É verdade que o romance não andava, encrencado miseravelmente no segundo capítulo. Em todo o caso sempre era uma tentativa. ${ }^{21}$

Em nossas últimas citações do romance, percebe-se um sentimento de clara frustração, pautado também num choque espaço-temporal que é, aparentemente - devido à quase ausência de tratamento dele -, não tão dramático quanto em Angústia. À medida que Graciliano Ramos mais se debruça sobre o âmago das suas personagens, mais pungentes tornam-se os conflitos entre o eu e o mundo, veiculados pelo uso de diferentes recursos, como o monólogo interior, que pode radicalizar a interioridade.

A desarmonia de João Valério em relação a sua vida é representada, igualmente, no afã de devanear sobre um local em que estaria não apenas numa situação economicamente superior, mas, também, em condição mais favorável no que tange à atribulada vida sentimental. O futuro desejado pelo pobre-diabo - designado por José Paulo Paes ${ }^{22}$ como aquele que reiteradamente pensa em dinheiro, pois, sobrevivendo com um baixo salário, está sempre à beira da ruína - contrasta com o presente inquietante:

Imaginei-me proprietário, vendendo tudo, arredondando aí uns quinhentos contos, indo viver no Rio de Janeiro com Marta, entre romances franceses, papéis de música e flores de parafina. Onde iria morar? Na Tijuca, em Santa Teresa, ou em Copacabana, um dos bairros que vi nos jornais. Eu seria um marido exemplar e Marta uma companheira deliciosa, dessas fabricadas por poetas solteiros. ${ }^{23}$

Outro ângulo que mostra, no mínimo, um incômodo em relação ao meio é o modo como ele se caracteriza fisicamente, vendo-se em discordância com a maioria dos habitantes daquela cidade: "Veio-me um pensamento agradável. Talvez gostasse de mim. Era possível. Olhei-me ao espelho. Tenho o nariz bem-feito, os olhos azuis, os dentes brancos, o

21. Idem, p. 14.

22. PAEs, José Paulo. "O pobre-diabo no romance brasileiro". In: Armazém literário: ensaios. São Paulo: Companhia das Letras, 2008, pp. 52-3.

23. RAMOS, Graciliano. Op. cit., pp. 42-3. João Valério ironiza, evocando características irretocáveis das mulheres criadas por poetas inexperientes em questões amorosas. Tal ironia corrobora a condição fantasiosa das suas aspirações, uma vez que tanto a situação financeira imaginada quanto os atributos da desejada esposa são inatingíveis. 
cabelo louro - vantagens". ${ }^{24}$ Com essas "vantagens", ele poderia, junto com Luísa, gerar filhos "muito bonitos"; eles, num porvir fantasioso, em outro desvario de João Valério,

cresceram gordos, vermelhos, dois machos e duas fêmeas. À meia-noite andávamos pelo Rio de Janeiro; os rapazes estavam na academia, tudo sabido, quase doutor, uma pequena tinha casado com um médico, a outra com um fazendeiro - e nós íamos no dia seguinte visitá-las em São Paulo. ${ }^{25}$

O devaneio de insone é interrompido pelos sons da realidade da pensão em que mora. As imagens edênicas de um futuro formidável são cortadas pelo arrebatamento diante da vida que, de fato, vive: "Um cão uivava na rua; os galos entraram a cantar. $\mathrm{O}$ dr. Liberato pigarreava; Isidoro Pinheiro roncava o sono dos justos; esmoreciam no corredor as pisadas sutis do Pascoal e um rumor, também sutil, na porta do quarto de $d$. Maria José." ${ }^{26}$

Se o escapismo de João Valério é demarcado pela constante evasão do presente e pelo sonho com um futuro paradisíaco, ele também é revelado no processo de escrita - mal executado - do seu romance. Temos aqui o embrião, pelo ato de escrever, da personagem altamente autocrítica de Angústia, bem como a de São Bernardo (1934), salientada pela crítica.

Nas menções do protagonista às dificuldades de construção do romance, é mostrada a predileção do autor - vista em suas cartas e em seus artigos - por figurar uma realidade lucidamente examinada por ele, como participante e/ou como exímio observador. O autor de Vidas secas (1938) transporta para o fazer do romance dentro do romance - João Valério, em Caetés, analisando a escrita de sua obra sobre os índios caetés - os seus ideais em relação à atitude artística do intelectual. Dessa forma, como o narrador de Caetés poderia elaborar um livro a respeito do que lhe é tão distante? João Valério, atestando que a história está emperrada, assevera:

Também aventurar-me a fabricar um romance histórico sem conhecer história! Os meus caetés realmente não têm verossimilhança, porque deles apenas sei que existiram,

\footnotetext{
24. Idem, p. 24.

25. Idem, p. 25.

26. Ibidem.
} 
andavam nus e comiam gente. Li, na escola primária, uns carapetões interessantes no Gonçalves Dias e no Alencar, mas já esqueci quase tudo. Sorria-me, entretanto, a esperança de transformar esse material arcaico numa brochura de cem a duzentas páginas, cheia de lorotas em bom estilo, editada no Ramalho.

Corrigi os erros, pus um enfeite a mais na barriga de um caboclo, cortei dois advérbios - e passei meia hora com a pena suspensa. ${ }^{27}$

Os descompassos na reconstituição da vida dos caetés são enormes. Bem sabemos que Gonçalves Dias e José de Alencar representaram a vida indígena pautados na ideologia do embelezamento da natureza e das qualidades positivas dos nativos, à cata de um passado glorioso, fazendo uso da forma romance, recém-chegada ao Brasil. João Valério quer ser reconhecido, décadas depois dos escritores românticos, procurando um pouco de fama em "lorotas em bom estilo". ${ }^{28} \mathrm{O}$ empenho do narrador-personagem, porém, é frustrante.

Retomando nosso objetivo, perceba-se que o sentimento de frustração diante da realidade desoladora é amplificado nos momentos de introspecção das personagens. Podemos assinalar mais dois momentos em que há a supervalorização do interior do narrador-protagonista, que será fulcral em romances posteriores.

\section{TENSÃO INTERIORIZADA E INAÇÃO}

A primeira passagem traz a visão cambiante de João Valério direcionada a Luísa - muito bem notada por Carina Ferreira Lessa ${ }^{29}$ : ela é, em alguns instantes, venerada, e, em outros, odiada, havendo, ainda, trechos em que o narrador-protagonista reflete sobre essas alterações de julgamento. Vejamos, respectivamente, veneração, ódio, dúvida, nos exemplos:

Bradei: "Luísa me ama! Estrelas do céu, Luísa me ama!". Imaginei que as estrelas do céu ficavam cientes e isso me deu satisfação. Uma delas tremeluziu mais que as outras, respondeu-me de lá, vermelha e grande. Desejei saber o nome daquele sol complacente.

27. Idem, pp. 23-4.

28. Idem, p. 24.

29. LESSA, Carina Ferreira. Graciliano Ramos: o desarranjo interior e a estética da memória. Tese de Doutorado. UfRJ, Rio de Janeiro, 2016, p. 71. 
Belatriz? Altair? Aldebarã? Não conheço nenhum. Se eu fosse selvagem, metê-lo-ia entre os meus deuses..$^{30}$

$[\ldots]$

Patife! Luísa já não era a santa que imaginei. Tinha descido. Mas, quando estava alguns dias sem a ver, eu descobria nela todas as perfeições. ${ }^{31}$

$[\ldots]$

Como a gente cega! Talvez comigo se desse o mesmo. Não que Luísa fosse como Clementina. Graças a Deus tenho bons olhos, bom olfato, sei o que está limpo e o que é feio. Mas todas as belas qualidades com que me entretive a enfeitar o meu ídolo seriam o que eu julgava? ${ }^{32}$

Nessas sondagens do interior, o protagonista medita sobre as qualidades de Luísa por meio, obviamente, de sua perspectiva, muitas vezes envenenada pela frustração. Dada a ênfase na veneração, no ódio e na dúvida, é possível presumir que a mulher de Adrião seja motivo de grandes abalos emocionais em João Valério. Entretanto, ele não age quando a oportunidade de se unir, legalmente, a Luísa desponta após a morte do marido dela. Aliás, Isidoro, um dos amigos de Valério, afirma que, havendo boatos de uma relação amorosa entre o protagonista e Luísa, o casamento é um compromisso necessário:

- Não há ponderação - atalhou Isidoro. - O que há é que você deve casar com a moça, está é que a ponderação. Não sei o que houve entre os dois. Provavelmente não houve nada. Ou talvez tenha havido. Isso é lá segredo seu. O que é certo é que rosnaram por aí, você andava doido por ela e o Adrião deu o couro às varas. ${ }^{33}$

Linhas após relatar a recomendação do amigo, o narrador atesta que considerou o assunto: "Muitas vezes me ocorrera o que Isidoro acabava de sugerir-me. Indecisão". ${ }^{34}$ Entre a ação e a inação, ele escolhe a segunda opção, debatendo-se internamente:

\footnotetext{
30. RAmos, Graciliano. Op. cit., p. 119.

31. Idem, p. 178.

32. Idem, p. 175 .

33. Idem, p. 240.

34. Ibidem.
} 
Dois meses sem ver Luísa. À noite distraía-me a repetir a mim mesmo que ainda a amava e havia de ser feliz com ela. Hipocrisia: todos os meus desejos tinham murchado. Tentei renová-los, recompus mentalmente os primeiros encontros, na ausência de Adrião, entrevistas a furto no jardim, a tarde que passamos no Tanque, sob árvores. Mas apenas consegui recordar com viveza um raio de sol que atravessava a ramagem e vinha arrastar-se na pedra coberta de musgo, a garça displicente, um sinal escuro que Luísa tem abaixo do seio esquerdo. Lembrei-me também de me haver ela uma vez plantado os dentes no pescoço. Ao cabo de algumas horas a parte mordida estava vermelha e necessitando o disfarce de uma rodela de pano. Depois a mancha se havia tornado gradualmente esverdeada, amarelada, afinal desaparecera. ${ }^{35}$

Assim como a mancha fugaz no pescoço de Luísa, o sentimento do protagonista não se mostra indelével; ao contrário, a vacilação gera uma enorme indiferença, muito diferente das perturbações apaixonadas de outrora.

Outra passagem que nos leva ao âmago de João Valério é observada ao final do romance, quando ele se vê em grande aturdimento. Esse talvez seja o instante da maior exploração interior, acentuando mais profundamente o sentimento de inadaptabilidade. $\mathrm{Na}$ reconstituição da vida dos caetés, ele busca afinidades com a sua. Ele é e não é um caeté. Prostrado na reedificação do passado, também não consegue desvencilhar-se de Palmeira dos Índios. Reconstruindo algo pouco aderente a ele e devaneando um futuro paradisíaco, ele se instala ad infinitum no presente, como o indivíduo médio que está fadado a sempre ser, muito devido à sua prostração. Ele não é selvagem, como os caetés, nem totalmente civilizado para habitar o Rio de Janeiro e São Paulo. Vemos esse choque na consciência da personagem no monólogo do último capítulo:

Não ser selvagem! Que sou eu senão um selvagem, ligeiramente polido, com uma tênue camada de verniz por fora? Quatrocentos anos de civilização, outras raças, outros costumes. E eu disse que não sabia o que se passava na alma de um caeté! Provavelmente o que se passa na minha, com algumas diferenças. Um caeté de olhos azuis, que fala português ruim, sabe escrituração mercantil, lê jornais, ouve missas. É isto, um caeté.

$[\ldots]$

35. Idem, pp. 240-1. 
Diferenças também, é claro. Outras raças, outros costumes, quatrocentos anos. Mas no íntimo, um caeté. Um caeté descrente.

Descrente? Engano. Não há ninguém mais crédulo que eu. E esta exaltação, quase veneração, com que ouço falar em artistas que não conheço, filósofos que não sei se existiram! Ateu! Não é verdade. Tenho passado a vida a criar deuses que morrem logo, ídolos que depois derrubo - uma estrela no céu, algumas mulheres na terra... ${ }^{36}$

Apenas interiormente a comodidade da vida de pequeno burguês de João Valério é abalada. Ele se rende ao mundo provinciano, à vivência dos costumes de Palmeira dos Índios, desistindo tanto de Luísa quanto de escrever o romance sobre os índios: "Abandonei definitivamente os caetés: um negociante não se deve meter em coisas de arte". ${ }^{37}$ Todo o capítulo $\mathrm{xxx}$ - o penúltimo da obra - relata a rotina pacata do protagonista, que nela passa a encontrar satisfação, como é possível atestar, por exemplo, na adjetivação do seguinte trecho:

Continuo na pensão de d. Maria José, mas aos domingos janto com Vitorino. Quase sempre vai Isidoro. A Teixeira, excelente dona de casa, traz aquilo muito bonito. Há no salão duas paisagens a óleo. Os móveis da sala de jantar foram substituídos por outros, onde porcelanas e cristais novos brilham. Uma habitação confortável..$^{38}$

Entretanto, a desestruturação do equilíbrio de João Valério torna-se grave no capítulo posterior, quando, avistando o açude, relembra Luísa. Tomado por lembranças, ele entra "a vagar pela cidade, maquinalmente, levado por uma onda de recordações", 39 que o conduzem a passar a limpo os acontecimentos e as suas atitudes diante deles, numa autoinvestigação aflita sobre o que ele de fato é. Os movimentos finais do romance - nos capítulos XXx e XXXI - sintetizam o que ocorre em algumas ocasiões no livro, isto é, a passagem da crônica de costumes - muitas vezes encobrindo o mal-estar da personagem - para a introspecção - acentuando as suas perturbações e o sentimento de não pertencimento.

\footnotetext{
36. Idem, pp. 250-2.

37. Idem, p. 245.

38. Idem, p. 246, grifos nossos.

39. Idem, p. 249.
} 
É num tom de total amargura, como vemos na citação referente às páginas 2502, que o romance termina. Término, aliás, fenomenal, que figura como um dos pontos altos da sondagem psicológica de Graciliano Ramos, apontando para o que estava por vir. Caetés, como romance de estreia, inaugura, mesmo que incipientemente, alguns ângulos de visão situados no horizonte do escritor alagoano que, em obras posteriores, serão mais bem elaborados - como o aviltamento do que o rodeia e a constante autoanálise do protagonista.

A narração de costumes em Caetés resulta numa forma/conteúdo bem distinta da de Angústia, por exemplo, em que o extremo da inadaptação é representado nas associações tresloucadas e incontroláveis dos monólogos de Luís da Silva no que toca a pessoas e imagens tanto do seu passado mais próximo, quanto do mais longínquo. Indo ao encontro das ideias de Luís Bueno, concordamos que Angústia expande o que em Caetés é representado de forma embrionária. Ambos trabalham

mais ou menos com a mesma equação: a do intelectual oriundo de uma aristocracia rural decadente que tem dificuldade em ver-se socialmente diminuído. O que muda são alguns termos dessa equação, que resulta bastante linear no primeiro livro e muito complexa no outro. ${ }^{40}$

Enquanto Luís da Silva é insistentemente inconformado, age sobre a sua insatisfação, mete-se no mundo, tenta "a vida como soldado", decai como "vagabundo e se reabilita na capital, como funcionário público e crítico literário", nunca encontrando descanso, remoendo febrilmente as mesmas ideias, numa inquietação violenta, João Valério, resignado, "aceita a sociedade no armazém dos Teixeira como reabilitação plena e se satisfaz" ${ }^{41}$ Tais protagonistas partilham uma ânsia enorme de serem aceitos e, principalmente, assim como Paulo Honório, de aceitarem a si e ao seu passado, porém de forma muito distinta.

Antonio Candido ${ }^{42}$ também assinala o tratamento diverso no modo como os sentimentos do narrador-protagonista são construídos em Caetés e nas obras posteriores de Graciliano ganhando nova dimensão: "Esse impulso irrefletido, essa irritação

40. BUENo, Luís. "Posfácio: uma grande estreia”. In: Ramos, Graciliano. Op. cit., p. 265.

41. Ibidem.

42. CANDIDO, Antonio. Op. cit., p. 22. 
com as regras sociais, mal pressagiam, aqui, o vulto que haverão de assumir nos livros posteriores". Mal pressagiam, contudo pressagiam. Já Hélio Pólvora diz que

Caetés demonstra que o universo ficcional de Graciliano, limitado a aspectos de sua vida e experiência, alimenta-se de temas e personagens recorrentes que, já na estreia, feriam a sensibilidade do escritor, deixavam marcas perenes. Sem o João Valério [...] não existiria o Paulo Honório $[\ldots]$ e, mais acentuadamente, o Luís da Silva $[\ldots] .{ }^{43}$

Pólvora ${ }^{44}$ afirma, ainda, que Caetés é um "romance-síntese, o referencial de toda a obra do mestre". De fato, é necessário que se investigue o livro de estreia para que se obtenha uma interpretação cabível das outras obras do escritor de Vidas secas, que nunca escondeu - principalmente em cartas e artigos - a sua poética relacionada ao grau de empirismo contido em seus livros. ${ }^{45} \mathrm{~A}$ percepção mais lúcida dos outros livros, advinda da leitura de Caetés, tem muito a ver com as similaridades e diferenças na constituição das personagens introspectivas de Graciliano - "sujeitos carregados de tiques, consumidos por uma ideia fixa, presos a qualquer singularidade maníaca". ${ }^{6}$ Aliás, a menor introspecção em Caetés gera uma personagem que não se remete tanto ao ato reminiscente. Os choques em relação ao passado são mais brandos, e a sua relação com ele não vem à tona a todo momento, ou, como assinala Luís Bueno, "Valério prega esse passado com apenas um golpe de martelo e procura esquecê-lo".47

Reafirmemos que no romance, que se movimenta entre a crônica de costumes e a interiorização do protagonista, a narração dos hábitos de classe daquele universo provinciano é mais volumosa do que a introspecção. O livro se equilibra, desse modo, entre a tensão mínima e a interior, diferentemente de São Bernardo e de Angústia, em que as tensões crítica e interior são exploradas incisivamente. Além de João Valério não ser cindido como Paulo Honório ou, mais acentuadamente, como Luís da Silva, o

\footnotetext{
43. PÓlvora, Hélio. Op. cit., p. 89.

44. Idem, p. 96.

45. Em carta à irmã Marili, Graciliano sintetiza essa atitude artística: "Só conseguimos deitar no papel os nossos sentimentos, a nossa vida. Arte é sangue, é carne”. RAMos, Graciliano. Cartas. 8 ed. Rio de Janeiro: Record, 2011, p. 293.

46. GRIECO, Agripino. “Graciliano Ramos: Caetés”. In: Brayner, Sônia. (org.). Graciliano Ramos. Rio de Janeiro: Civilização Brasileira/MEC, 1977 (Col. Fortuna Crítica, 2), p. 150.

47. BUENo, Luís. “Posfácio: uma grande estreia”. In: RAmos, Graciliano. Op. cit., p. 265.
} 
romance é narrado de forma mais linear e contida. As tensões histórico-sociais mais tênues não reclamam um tratamento oscilatório da matéria espaço-temporal, como em Angústia, por exemplo. Enquanto em São Bernardo topamos com uma perscrutação interior mais radicalizada do que em Caetés, amplificando a tragédia do sujeito e a sua tensão com o mundo.

Pedro Barbosa Rudge Furtado é discente, como doutorando, do Programa de pós-graduação em Estudos Literários da FCL/Unesp - Araraquara. É graduado em letras pela mesma universidade e mestre pelo mesmo programa com a dissertação "Rememoração em Graciliano Ramos: do romance à autobiografia" (2017). Concentra-se no estudo da literatura brasileira, principalmente da prosa do decênio de 1930.

Maria Célia Leonel é docente do Programa de pós-graduação em Estudos Literários da FCL/ Unesp - Araraquara, onde é professora titular. Publicou Estética emodernismo (HUCITEC/Instituto Nacional do Livro, 1984), Guimarães Rosa: magma e gênese (Ed. Unesp, 2000) e Ficção e ensaio: literatura e história no Brasil (EdUFSCar, 2014, com J. A. Segatto). 